\title{
ESTRESSE SALINO EM PLÂNTULAS DE MILHO: PARTE II DISTRIBUIÇÃO DOS MACRONUTRIENTES CATIÔNICOS E SUAS RELAÇÕES COM SÓDIO ${ }^{1}$
}

\author{
André Dias de Azevedo Neto ${ }^{2}$ \& José Nildo Tabosa ${ }^{3}$
}

\begin{abstract}
RESUMO
Este trabalho foi conduzido em casa de vegetação, com o objetivo de se avaliar o efeito do estresse salino sobre a distribuição de nutrientes em cultivares de milho com tolerância diferenciada à salinidade. Foi utilizado um arranjo fatorial 2 x 5 com duas cultivares de milho (P-3051 e BR-5011) e cinco níveis de $\mathrm{NaCl}$ na solução nutritiva $\left(0,25,50,75\right.$ e $\left.100 \mathrm{~mol} \mathrm{~m}^{-3}\right)$. O estresse salino elevou as concentrações de $\mathrm{Na}^{+}$ e reduziu as de $\mathrm{K}^{+}$em todas as partes das plantas. Foi observada acumulação preferencial de $\mathrm{Na}^{+}$nos tecidos do colmo e da bainha, em detrimento dos tecidos do limbo. Os teores de $\mathrm{Ca}^{++}$foram diminuídos na raiz, no colmo e limbo das plantas, enquanto os de $\mathrm{Mg}^{++}$só diminuíram na raiz e no colmo. No nível $100 \mathrm{~mol} \mathrm{~m}^{-3} \mathrm{de} \mathrm{NaCl}$, os teores de $\mathrm{Ca}^{++}$nas raízes da cultivar P-3051 foram cerca de $60 \%$ mais elevados que os da BR-5011. A salinidade incrementou as relações $\mathrm{Na}^{+} / \mathrm{K}^{+}, \mathrm{Na}^{+} / \mathrm{Ca}^{++}$e Na $/ \mathrm{Mg}^{++}$em todas as partes das plantas, sendo este acréscimo mais evidente na cultivar BR-5011 que na P-3051.
\end{abstract}

Palavras-chave: nutrição mineral, potássio, cálcio, magnésio

\author{
SALT STRESS IN MAIZE SEEDLINGS: PART II \\ DISTRIBUTION OF CATIONIC MACRONUTRIENTS AND \\ ITS RELATION WITH SODIUM
}

\begin{abstract}
The work was performed in the greenhouse, aiming to evaluate the effect of salt stress on distribution of nutrients in different parts of maize cultivars differing in their tolerance to salinity. The experiment was carried out on $2 \times 5$ factorial arrangement with two maize cultivars (P-3051 and BR-5011) and five sodium chloride levels in nutrient solution $\left(0,25,50,75\right.$ or $\left.100 \mathrm{~mol} \mathrm{~m}^{-3}\right)$. Salt stress increased $\mathrm{Na}^{+}$ content and decreased $\mathrm{K}^{+}$content in all plant parts. $\mathrm{Na}^{+}$content was higher in stalk and sheath than in leaf blade tissue. $\mathrm{Ca}^{++}$content decreased in root, stalk and leaf blade while $\mathrm{Mg}^{++}$content decreased only in root and in stalk tissue. Root $\mathrm{Ca}^{++}$content in the cultivar P-3051 under $100 \mathrm{~mol} \mathrm{~m}^{-3} \mathrm{NaCl}$ was $60 \%$ higher than in the cultivar BR-5011. The salt treatment increased $\mathrm{Na}^{+} / \mathrm{K}^{+}, \mathrm{Na}^{+} / \mathrm{Ca}^{++}$and $\mathrm{Na}^{+} / \mathrm{Mg}^{++}$ ratios in all plant parts, and the increment was higher in the P-3051 than in the BR-5011 cultivar.
\end{abstract}

Key words: mineral nutrition, potassium, calcium, magnesium

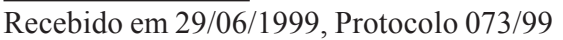

${ }^{1}$ Parte da Dissertação de Mestrado do primeiro autor

${ }^{2}$ MSc. Fisiologia Vegetal, Pesquisador Dep. Química/UFRPE. Rua D. Manoel de Medeiros s/n, Dois Irmãos, Recife, PE. CEP 52171 - 900. Fone: (0xx81) 441 4577, Ramal 355, Fax: (0xx81) 441 4697. E-mail: aazevedo@ipa.br

${ }^{3}$ MSc. Melhoramento Vegetal, Pesquisador IPA, Bolsista CNPq. Av. Gal. San Martin, 1371, Bonji, Recife, PE. CEP 50761 - 000. Fone: (0xx81) 445 2200, Ramal 174, Fax: (0xx81) 227 4017.E-mail: tabosa@ipa.br 


\section{INTRODUÇÃO}

A inibição do crescimento das plantas pelo estresse salino pode ser causada pela redução do potencial osmótico e/ou acumulação excessiva de íons, o que pode induzir a toxicidade iônica, desequilíbrio nutricional ou a ambos (Greenway \& Munns, 1980; Munns \& Termaat, 1986; Cusido et al., 1987; Boursier \& Läuchli, 1990). Entretanto o grau com que cada um desses componentes do estresse salino influencia o crescimento é dependente de muitos fatores, ou seja, da espécie vegetal, da cultivar, do tipo de salinidade, da intensidade e da duração do estresse salino, da luminosidade, da umidade do solo e do ar e do estádio de desenvolvimento da planta (Cramer et al., 1994).

A resposta das plantas à salinidade é um fenômeno complexo, envolvendo alterações morfológicas e de crescimento, além de processos físiológicos e bioquímicos (Fougère et al., 1991). Assim, a sobrevivência em ambientes salinos pode resultar de processos adaptativos envolvendo absorção, transporte e distribuição de íons nos vários órgãos da planta e sua compartimentação dentro das células (Munns \& Termaat, 1986).

Os íons inorgânicos desempenham importante papel na preservação do potencial hídrico vegetal; portanto, mecanismos em plantas conduzindo ao excesso de absorção iônica e exclusão de $\mathrm{Na}^{+}$e $\mathrm{Cl}^{-}$de tecidos metabolicamente ativos da parte aérea, podem ser responsáveis pela tolerância das culturas ao estresse salino (Greenway \& Munns, 1980; Cheeseman, 1988). Esta exclusão pode ser efetuada através da acumulação preferencial de íons em tecidos relativamente tolerantes da raiz ou da parte aérea (Boursier et al., 1987).

Como os antagonismos iônicos em ambientes salinos são usualmente seguidos pelas deficiências nutricionais, a composição iônica é muito importante no que diz respeito à tolerância ao estresse salino (Ullah et al., 1993). Por outro lado várias relações iônicas podem ser importantes na determinação de toxicidades relativas de vários íons, cujo estudo pode revelar discernimento entre antagonismos iônicos que não estejam evidentes, quando apenas concentrações absolutas são consideradas (Cramer et al., 1994).

Assim, este trabalho teve por objetivo estudar a distribuição de macronutrientes catiônicos e suas relações com o sódio nas partes (raiz, colmo, bainha e limbo) de duas cultivares de milho com tolerância diferenciada à salinidade, quando submetidas a diferentes níveis de cloreto de sódio na solução nutritiva.

\section{MATERIAL E MÉTODOS}

O trabalho foi conduzido na casa de vegetação do Departamento de Química da UFRPE, no período de julho a dezembro de 1995. Foram utilizadas duas cultivares de milho, sendo uma tolerante (P-3051) e uma sensível (BR-5011) à salinidade, quando comparadas entre si. Estas cultivares foram previamente selecionadas em "screening" entre 29 diferentes materiais indicados para o Estado de Pernambuco (Azevedo Neto, 1997). Foram utilizados cinco níveis de cloreto de sódio $\left(0,25,5075\right.$ e $\left.100 \mathrm{~mol} \mathrm{~m}^{-3}\right)$ na solução nutritiva de Hoagland \& Arnon (1950).

As características das soluções nutritivas utilizadas no experimento (Condutividade Elétrica-CE e Potencial Osmótico $-\psi_{\text {os }}$ ) constam na Tabela 1. A CE da solução referente ao nível $0 \mathrm{~mol}$ $\mathrm{m}^{-3}$ de $\mathrm{NaCl}$ equivale à de solos não salinos; as $\mathrm{CE}$ dos níveis 25 e $50 \mathrm{~mol} \mathrm{~m}^{-3}$ de $\mathrm{NaCl}$ equivalem às de solos medianamente salinos e as $\mathrm{CE}$ dos níveis 75 e $100 \mathrm{~mol} \mathrm{~m}^{-3} \mathrm{de} \mathrm{NaCl}$, equivalem às de solos fortemente salinos (Richards, 1974).

Tabela 1. Características das soluções nutritivas referentes aos tratamentos salinos utilizados no experimento

\begin{tabular}{ccc}
\hline $\begin{array}{c}\text { Níveis de NaCl } \\
\left(\mathrm{mol} \mathrm{m}^{-3}\right)\end{array}$ & $\begin{array}{c}\text { Condutividade } \\
\text { Elétrica }^{1}\left(\mathrm{dS} \mathrm{m}^{-1}\right)\end{array}$ & $\begin{array}{c}\text { Potencial } \\
\text { Osmótico }^{2}(\mathrm{MPa})\end{array}$ \\
\hline 0 & 2,0 & $-0,07$ \\
25 & 4,6 & $-0,20$ \\
50 & 7,1 & $-0,32$ \\
75 & 9,6 & $-0,43$ \\
100 & 12,0 & $-0,57$ \\
\hline
\end{tabular}

${ }^{1}$ Determinado por meio de condutivímetro Metrohm 644

${ }^{2}$ Calculado de acordo com Wyn Jones \& Gorham (1983)

As sementes foram postas para germinar em recipientes do tipo "germbox", forrados com papel mata-borrão umedecidos com água destilada. Aos 7 dias após a germinação, as plântulas foram transferidas para as respectivas unidades experimentais, as quais constaram de vasos de polietileno com capacidade para 2,5 L. Em cada vaso foi colocada uma plântula, ficando o sistema radicular imerso na solução nutritiva, acrescida ou não de cloreto de sódio, conforme o tratamento. Utilizaram-se mini-compressores de ar para promover a aeração da solução nutritiva e, consequentemente, a oxigenação do sistema radicular. As soluções nutritivas foram repostas diariamente e renovadas semanalmente, até a coleta do material, a qual se processou 21 dias após o início dos tratamentos salinos, e onde as plântulas foram subdivididas em raiz, colmo, bainha e limbo. O sistema radicular de cada plântula foi submetido a uma lavagem rápida (cerca de $10 \mathrm{seg}$ ) em água destilada e, em seguida, enxugado com papel-toalha, a fim de se retirar a solução nutritiva do mesmo.

Foram procedidas as análises químicas dos elementos sódio, potássio, cálcio e magnésio, conforme descrito por Sarruge \& Haag (1974). Em virtude do material do colmo das plantas ser, no nível $100 \mathrm{~mol} \mathrm{~m}^{-3}$ de $\mathrm{NaCl}$, insuficiente para todas as análises químicas, as cinco repetições foram reunidas em uma única amostra e analisadas conjuntamente. Assim os dados de composição química do colmo referentes a este nível de salinidade não foram utilizados nas análises estatísticas. Os resultados foram analisados estatisticamente e as médias foram comparadas pelo teste de Tukey, a nível de 5\% de probabilidade, conforme Gomes (1987).

\section{RESULTADOS E DISCUSSÃO}

\section{Sódio}

O teor de sódio nas partes das plantas cresceu significativamente com o incremento dos níveis de cloreto de sódio na solução nutritiva, em ambas as cultivares estudadas (Tabela 2). Entretanto a partir do tratamento $25 \mathrm{~mol} \mathrm{~m}^{-3}$ de $\mathrm{NaCl}$, os acréscimos nos teores de sódio foram mais evidentes nos tecidos da parte aérea que na raiz. Comparando-se as partes das plantas, verifica-se que os maiores teores de sódio foram encontrados na raiz, no colmo e na bainha correspondendo, respectivamente, a cerca de $1,8,2,8$ e 2,1 vezes aos observados no limbo, no nível $100 \mathrm{~mol} \mathrm{~m}^{-3} \mathrm{de} \mathrm{NaCl}$. 
Tabela 2. Teores ${ }^{1}$ de sódio, potássio, cálcio e magnésio na matéria seca das diferentes partes das cultivares de milho P-3051 (tolerante) e BR-5011 (sensível) aos 21 dias após o transplantio, em função dos níveis de NaCl utilizados na solução nutritiva

\begin{tabular}{|c|c|c|c|c|c|c|c|c|}
\hline \multirow{3}{*}{$\begin{array}{l}\text { Níveis de } \\
\left.\mathrm{NaCl}^{-3}\right) \\
\left(\mathrm{mol} \mathrm{m}^{-3}\right)\end{array}$} & \multicolumn{8}{|c|}{ Partes das Plantas } \\
\hline & \multicolumn{2}{|c|}{ Raiz } & \multicolumn{2}{|c|}{ Colmo } & \multicolumn{2}{|c|}{ Bainha } & \multicolumn{2}{|c|}{ Limbo } \\
\hline & P-3051 & BR-5011 & P-3051 & BR-5011 & P-3051 & BR-5011 & P-3051 & BR-5011 \\
\hline & \multicolumn{8}{|c|}{$\mathrm{Na}^{+}\left(\mathrm{g} \mathrm{kg}^{-1}\right)$} \\
\hline 0 & $1,02 \mathrm{Ac}$ & $1,22 \mathrm{Ad}$ & $1,28 \mathrm{Ad}$ & $1,53 \mathrm{Ad}$ & $0,82 \mathrm{Ad}$ & $0,85 \mathrm{Ae}$ & $0,81 \mathrm{Ad}$ & $1,02 \mathrm{Ad}$ \\
\hline 25 & $35,33 \mathrm{Ab}$ & $37,78 \mathrm{Ac}$ & $41,35 \mathrm{Bc}$ & 46,97Ac & $18,38 \mathrm{Ac}$ & $20,76 \mathrm{Ad}$ & $12,25 \mathrm{Ac}$ & $11,64 \mathrm{Ac}$ \\
\hline 50 & $46,97 \mathrm{Aa}$ & $45,74 \mathrm{Ab}$ & $61,26 \mathrm{Bb}$ & $66,88 \mathrm{Ab}$ & $26,54 \mathrm{Ac}$ & $29,27 \mathrm{Ac}$ & $17,77 \mathrm{Ab}$ & $17,56 \mathrm{Ab}$ \\
\hline 75 & $49,62 \mathrm{Aa}$ & $46,97 \mathrm{Ab}$ & $69,17 \mathrm{Ba}$ & $102,10 \mathrm{Aa}$ & $48,11 \mathrm{Ab}$ & $46,97 \mathrm{Ab}$ & $22,82 \mathrm{Aab}$ & $22,05 \mathrm{Ab}$ \\
\hline 100 & $53,09 \mathrm{Aa}$ & $53,78 \mathrm{Aa}$ & $64,94 *$ & $100,06^{*}$ & $59,22 \mathrm{Ba}$ & $64,70 \mathrm{Aa}$ & $28,38 \mathrm{Aa}$ & $30,99 \mathrm{Aa}$ \\
\hline \multirow[t]{2}{*}{ C. V. } & $9,52 \%$ & $9,52 \%$ & $8,26 \%$ & $8,26 \%$ & $14,78 \%$ & $14,78 \%$ & $18,19 \%$ & $18,19 \%$ \\
\hline & \multicolumn{8}{|c|}{$\mathrm{K}^{+}\left(\mathrm{g} \mathrm{kg}^{-1}\right)$} \\
\hline 0 & $28,59 \mathrm{Aa}$ & $28,59 \mathrm{Aa}$ & $84,15 \mathrm{Aa}$ & $68,95 \mathrm{Ba}$ & $64,89 \mathrm{Aa}$ & $61,85 \mathrm{Aa}$ & $32,04 \mathrm{Ba}$ & $36,10 \mathrm{Aa}$ \\
\hline 25 & $19,67 \mathrm{Ab}$ & $20,48 \mathrm{Ab}$ & $63,88 \mathrm{Ab}$ & $61,84 \mathrm{Aa}$ & $62,52 \mathrm{Aa}$ & $60,83 \mathrm{Aab}$ & $31,23 \mathrm{Aa}$ & $32,45 \mathrm{Aab}$ \\
\hline 50 & $15,41 \mathrm{Abc}$ & $17,64 \mathrm{Ab}$ & $49,68 \mathrm{Ac}$ & $36,50 \mathrm{Bb}$ & $56,78 \mathrm{Aa}$ & $49,34 \mathrm{Bbc}$ & $29,00 \mathrm{Aa}$ & $28,39 \mathrm{Abc}$ \\
\hline 75 & $12,83 \mathrm{Bc}$ & $18,92 \mathrm{Ab}$ & $36,50 \mathrm{Ac}$ & $13,18 \mathrm{Bc}$ & $39,04 \mathrm{Ab}$ & $38,02 \mathrm{Acd}$ & $20,94 \mathrm{Bb}$ & $25,96 \mathrm{Ac}$ \\
\hline 100 & $19,26 \mathrm{Ab}$ & $20,11 \mathrm{Ab}$ & $21,70 *$ & $7,10 *$ & $39,54 \mathrm{Ab}$ & $29,53 \mathrm{Bd}$ & $22,71 \mathrm{Ab}$ & $21,95 \mathrm{Ac}$ \\
\hline \multirow[t]{2}{*}{ C. V. } & $15,50 \%$ & $15,50 \%$ & $15,00 \%$ & $15,00 \%$ & $12,98 \%$ & $12,98 \%$ & $12,00 \%$ & $12,00 \%$ \\
\hline & \multicolumn{8}{|c|}{$\mathrm{Ca}^{++}\left(\mathrm{g} \mathrm{kg}^{-1}\right)$} \\
\hline 0 & $6,81 \mathrm{Aa}$ & $6,70 \mathrm{Aa}$ & $6,76 \mathrm{Aa}$ & $7,58 \mathrm{Aa}$ & $2,86 \mathrm{Bc}$ & $5,13 \mathrm{Aab}$ & $5,48 \mathrm{Aa}$ & $5,03 \mathrm{Aa}$ \\
\hline 25 & $5,40 \mathrm{Ab}$ & $4,83 \mathrm{Ab}$ & $6,40 \mathrm{Ba}$ & 7,99Aa & $4,14 \mathrm{Bb}$ & $5,71 \mathrm{Aa}$ & 4,54Aab & $4,50 \mathrm{Aa}$ \\
\hline 50 & $5,27 \mathrm{Ab}$ & $4,58 \mathrm{Bb}$ & $4,44 \mathrm{Bb}$ & 7,54Aa & $3,76 \mathrm{Bbc}$ & 4,53Aabc & 4,51Aab & 4,08Aab \\
\hline 75 & $3,83 \mathrm{Ac}$ & $2,46 \mathrm{Bc}$ & $3,88 \mathrm{Bb}$ & $7,95 \mathrm{Aa}$ & $5,61 \mathrm{Aa}$ & $3,72 \mathrm{Bc}$ & $3,94 \mathrm{Abc}$ & $2,79 \mathrm{Bc}$ \\
\hline 100 & $3,36 \mathrm{Ac}$ & $2,15 \mathrm{Bc}$ & $2,54 *$ & $4,94^{*}$ & 4,53ab & $4,14 \mathrm{Abc}$ & $3,29 \mathrm{Ac}$ & $3,19 \mathrm{Abc}$ \\
\hline \multirow[t]{2}{*}{ C. V. } & $14,66 \%$ & $14,66 \%$ & $13,20 \%$ & $13,20 \%$ & $15,37 \%$ & $15,37 \%$ & $13,68 \%$ & $13,68 \%$ \\
\hline & \multicolumn{8}{|c|}{$\mathrm{Mg}^{++}\left(\mathrm{g} \mathrm{kg}^{-1}\right)$} \\
\hline 0 & $9,23 \mathrm{Aa}$ & $9,95 \mathrm{Aa}$ & 7,65Aa & $7,62 \mathrm{Aa}$ & $3,83 \mathrm{Ba}$ & $4,81 \mathrm{Aa}$ & $3,41 \mathrm{Aa}$ & $3,15 \mathrm{Aa}$ \\
\hline 25 & 7,71Aab & $7,76 \mathrm{Ab}$ & 7,67Aa & $7,25 \mathrm{Aab}$ & $4,73 \mathrm{Aa}$ & $4,45 \mathrm{Aa}$ & $3,66 \mathrm{Aa}$ & $2,81 \mathrm{ABabc}$ \\
\hline 50 & 7,51 Aab & $8,28 \mathrm{Aab}$ & $6,94 \mathrm{Aa}$ & $5,80 \mathrm{Bbc}$ & $4,09 \mathrm{Aa}$ & $3,92 \mathrm{Aa}$ & $3,57 \mathrm{Aa}$ & $2,52 \mathrm{Bbc}$ \\
\hline 75 & $7,16 \mathrm{Abc}$ & $7,26 \mathrm{Ab}$ & $5,14 \mathrm{Ab}$ & $4,45 \mathrm{Ac}$ & $4,18 \mathrm{Aa}$ & $3,71 \mathrm{Aa}$ & $3,61 \mathrm{Aa}$ & $2,41 \mathrm{Bc}$ \\
\hline 100 & $5,38 \mathrm{Ac}$ & $4,66 \mathrm{Ac}$ & $4,23 *$ & $3,89 *$ & 4,33Aa & $3,69 \mathrm{Aa}$ & $3,27 \mathrm{Aa}$ & $3,08 \mathrm{Aab}$ \\
\hline C. V. & $13,40 \%$ & $13,40 \%$ & $14,20 \%$ & $14,20 \%$ & $15,45 \%$ & $15,45 \%$ & $9,94 \%$ & $9,94 \%$ \\
\hline
\end{tabular}

${ }^{1}$ Médias seguidas de mesmas letras, maiúsculas para cultivares e minúsculas para níveis, não diferem pelo teste de Tukey a nível de 5\%

*Amostras analisadas conjuntamente

Aumentos nas concentrações de sódio da parte aérea e raízes de plantas de milho cultivadas em ambientes salinos têm sido reportados por vários pesquisadores (Izzo et al., 1991; Alberico \& Cramer, 1993; Erdei \& Taleisnik, 1993). Semelhantemente ao observado neste trabalho, Cramer et al. (1994) verificaram aumentos nas concentrações de sódio da raiz, colmo, bainha e limbo de plântulas de milho cultivadas em condições de salinidade. Os autores mostraram, ainda, que o acúmulo de sódio na bainha foi superior ao das outras partes da planta.

A tendência de estabilização nos teores de sódio da raiz, observada em concentrações salinas médias e altas, pode representar uma saturação do mecanismo de retenção de sódio na raiz e, consequentemente, a capacidade finita deste órgão para atuar como reservatório de sódio para o limbo (Greenway \& Munns, 1980; Boursier et al., 1987; Boursier \& Läuchli, 1990).

À medida que as cultivares não diferiram quanto às concentrações de sódio na raiz e no limbo, pode-se considerar que a maior concentração deste íon no colmo e na bainha da BR-5011, tenha sido resultante de um maior influxo líquido de sódio nas raízes desta cultivar (Spickett et al., 1993). Diferenças na exclusão de sódio na superfície radicular, como resultado da diferença na permeabilidade ao sódio no plasmalema de células da epiderme e do córtex de cultivares de milho, foram descritas por Schubert \& Läuchli, 1990).
Tomando-se por base o nível mais elevado de salinidade, as concentrações de sódio no limbo das cultivares P-3051 e BR-5011 foram equivalentes, em termos de matéria fresca, a 191 e $194 \mathrm{~mol} \mathrm{~m}^{-3}$, respectivamente. Considerando-se que as concentrações citoplasmáticas de sódio em células adaptadas ou não à salinidade normalmente não excedem o limite de $100 \mathrm{~mol} \mathrm{~m}^{-3}$ (Binzel et al., 1988), as concentrações de $191 \mathrm{e}$ $194 \mathrm{~mol} \mathrm{~m}^{-3} \mathrm{de} \mathrm{Na}^{+}$foram suficientemente altas, necessitando de compartimentação iônica e/ou acumulação citoplasmática de solutos compatíveis, os quais podem reduzir a toxicidade iônica (Marcum \& Murdoch, 1994).

Portanto, o fato do teor de sódio no limbo da cultivar P-3051 não diferir da BR-5011, pode ser uma questão de compartimentação a nível subcelular (Alberico \& Cramer, 1993) haja vista a não identificação da real locação do sódio nas células do limbo no presente trabalho. É possível que a P-3051 tenha sido mais eficiente em isolar $\mathrm{Na}^{+}$nos compartimentos celulares que a BR-5011, reduzindo a toxicidade por este íon nos sítios metabolicamente ativos das folhas.

\section{Potássio}

A salinidade reduziu os teores de potássio em todas as partes das plantas, independentemente da cultivar analisada (Tabela 2). Na bainha e no limbo, os teores de potássio da cultivar BR-5011 declinaram significativamente desde o nível $50 \mathrm{~mol} \mathrm{~m}^{-3}$ de $\mathrm{NaCl}$, diferentemente da P-3051, no qual estes teores caíram de $75 \mathrm{~mol} \mathrm{~m}^{-3} \mathrm{de} \mathrm{NaCl}$ em diante. 
Analogamente ao verificado para sódio, os teores de potássio na raiz atingiram, de modo geral, um estado de equilíbrio a partir de $25 \mathrm{~mol} \mathrm{~m}^{-3} \mathrm{de} \mathrm{NaCl}$. Analisando-se conjuntamente as concentrações de potássio e sódio nas diferentes partes das plantas, verifica-se que o descréscimo nas concentrações de potássio ocorreu simultâneamente à elevação dos teores de sódio. $\mathrm{O}$ antagonismo verificado entre as concentrações desses nutrientes nas partes das plantas foi traduzido matematicamente através de elevados coeficientes de correlação negativa (Tabela 3), sugerindo a hipótese de que o aumento na concentração de sódio nos tecidos de espécies glicófitas geralmente está associado a uma diminuição na concentração de potássio (Greenway \& Munns, 1980).

Tabela 3. Coeficientes de correlação entre os teores de sódio e potássio das diferentes partes das cultivares de milho P-3051 (tolerante) e BR-5011 (sensível) aos 21 dias após o transplantio, em função dos níveis de $\mathrm{NaCl}$ utilizados na solução nutritiva Parte da Coef. Correlação (r) Valor de " $\mathrm{t}$ " Probabilidade $>$ "t"

\begin{tabular}{lllllll}
\cline { 4 - 6 } Planta & P-3051 & BR-5011 & P-3051 & BR-5011 & P-3051 & BR-5011
\end{tabular}

\begin{tabular}{lllllll}
\hline Raiz & $-0,81$ & $-0,72$ & 6,46 & 4,93 & 0,000020 & 0,000171
\end{tabular}

$\begin{array}{lllllll}\text { Colmo } & -0,93 & -0,88 & 10,79 & 8,05 & 0,000002 & 0,000007\end{array}$

$\begin{array}{lrrrrrr}\text { Bainha } & -0,90 & -0,84 & 9,78 & 7,26 & 0,000001 & 0,000008\end{array}$

\begin{tabular}{lllllll} 
Limbo & $-0,78$ & $-0,82$ & 5,88 & 6,69 & 0,000043 & 0,000016 \\
\hline
\end{tabular}

Diversos trabalhos avaliando o efeito do estresse salino sobre a concentração de potássio em plantas de milho, citam a redução nos teores deste nutriente com o incremento da salinidade (Kawasaki et al., 1983; Alberico \& Cramer, 1993; Rahman et al., 1993; Cramer et al., 1994).

$\mathrm{O}$ crescimento das diferentes partes das plantas foi menos afetado pela salinidade que as concentrações de potássio, indicando que a taxa de crescimento foi menos afetada que a taxa de absorção deste íon (Jarrell \& Beverly, 1981) devido, provavelmente, a um efeito adverso da salinidade sobre o metabolismo das raízes. Em adição (Kawasaki et al., 1983) citaram que o aumento da concentração de sódio no meio radicular pode inibir o influxo de potássio devido a relação competitiva entre cátions monovalentes. Alternativamente, tem-se mostrado que o estresse salino promove aumento no efluxo citossólico de potássio nas raízes das plantas; esta perda pode ser o resultado direto de trocas osmoticamente induzidas na permeabilidade do plasmalema, como também da substituição de cálcio por sódio na membrana, abrindo canais para potássio (Cramer et al., 1985).

\section{Cálcio}

Os tratamentos salinos promoveram a queda das concentrações de cálcio na raiz e no limbo de ambos os genótipos avaliados (Tabela 2). Contudo a cultivar P-3051 apresentou teores de cálcio mais elevados que a BR-5011 no limbo, no nível $75 \mathrm{~mol} \mathrm{~m}^{-3} \mathrm{de}$ $\mathrm{NaCl}$ e na raiz, a partir de $50 \mathrm{~mol} \mathrm{~m}^{-3} \mathrm{de} \mathrm{NaCl}$. Considerando-se o nível de $100 \mathrm{~mol} \mathrm{~m}^{-3} \mathrm{de} \mathrm{NaCl}$, a concentração de cálcio na raiz do tolerante foi cerca de $60 \%$ superior à do sensível.

Numerosos estudos têm demonstrado que a salinidade acarreta redução nos teores de cálcio em plantas de milho (Kawasaki et al., 1983; Izzo et al., 1991; Alberico \& Cramer, 1993; Cramer et al., 1994). Estes pesquisadores reportaram que a elevação na concentração de sódio na solução nutritiva ocasionou queda simultânea nos teores de cálcio de ambas, parte aérea e raízes, independente da característica adaptativa das cultivares estudadas, semelhante ao verificado nesse trabalho.

Tem-se proposto que altas concentrações de sódio no meio nutritivo deslocam o cálcio do plasmalema das células radiculares, resultando em uma perda da integridade da membrana e efluxo citossólico de solutos orgânicos e inorgânicos (Cramer et al., 1985). Em adição, trabalhos com plantas sob estresse salino têm demonstrado que a suplementação de cálcio reduz a acumulação líquida de sódio e mantém os níveis de potássio e metabólitos fostatados no tecido radicular, além de reduzir as perdas de fósforo (Colmer et al., 1994). Conseqüentemente, alterações em membranas biológicas onde o cálcio é um íon estabilizante, podem conduzir a uma sensibilidade maior da planta ao estresse salino, haja vista a importância da seletividade das membranas nos processos de absorção e compartimentação iônica.

Visto que o cálcio pode desempenhar importante papel na manutenção da integridade das membranas, os teores mais elevados deste nutriente, verificados na raiz da cultivar P-3051, devem ter contribuído, sobremaneira, para seu nível mais elevado de tolerância ao estresse salino, quando comparada com a BR-5011.

\section{Magnésio}

O comportamento dos dois genótipos quanto aos teores de magnésio das partes das plantas foi bastante semelhante, quando foram submetidos a aumentos sucessivos das concentrações de cloreto de sódio na solução nutritiva. Na raiz e no colmo, as concentrações de magnésio diminuíram com a salinidade, enquanto permaneceram relativamente constantes na bainha e no limbo (Tabela 2).

Comparando-se as partes das plantas, pode-se verificar que, em baixos níveis de cloreto de sódio na solução nutritiva, os maiores teores de magnésio foram encontrados na raiz e no colmo; entretanto, à medida que o estresse salino foi aumentado, as concentrações de magnésio nas diferentes partes das plantas aproximaram-se do equilíbrio.

A despeito da importância do magnésio no metabolismo vegetal, a literatura referente a estudos sobre as concentrações deste nutriente em plantas cultivadas sob estresse salino é bastante limitada, tanto para milho como para outras espécies vegetais. Em adição, os resultados encontrados são freqüentemente controversos. Desta forma, Hassan et al. (1970) verificaram que as concentrações deste nutriente nas folhas e no colmo de plantas de milho aumentaram com o incremento da salinidade. Os autores atribuíram, ainda, este resultado, aos teores bastante elevados de magnésio no solo (cerca de 6,0 meq $100 \mathrm{~g}^{-1}$ ).

Alternativamente, trabalhos com sorgo têm reportado que as concentrações de magnésio podem permanecer constantes na parte aérea (Azevedo Neto et al., 1995) ou diminuir na parte aérea e nas raízes (Kawasaki et al., 1983) com o incremento do estresse salino. Esta variabilidade de resultados realça a importância de maiores estudos sobre a influência da salinidade sobre os teores deste macronutriente nos diferentes tecidos vegetais.

Além do papel do magnésio na molécula de clorofila e da sua atividade como co-fator em quase todas as enzimas do metabolismo energético (Taiz \& Zeiger, 1991) este íon é requerido para a integridade dos ribossomos e contribui efetivamente para 
a estabilidade estrutural dos ácidos nucléicos e membranas (Clarkson \& Hanson, 1980). Desta forma, é provável que a redução nos teores desse nutriente tenha sido um dos fatores que afetaram o metabolismo das plantas e, conseqüentemente, reduziram o crescimento das cultivares estudadas.

\section{Relações sódio/potássio, sódio/cálcio e sódio/magnésio}

Independente da cultivar ou da parte da planta analisada, as relações $\mathrm{Na}^{+} / \mathrm{K}^{+}, \mathrm{Na}^{+} / \mathrm{Ca}^{++}$e $\mathrm{Na}^{+} / \mathrm{Mg}^{++}$mostraram-se invariavelmente crescentes, à medida que os níveis de cloreto de sódio na solução nutritiva foram aumentados (Tabela 3); todavia, este aumento foi, em geral, mais pronunciado para a cultivar BR-5011 que para a P-3051. Esta diferença foi particularmente evidente para a relação $\mathrm{Na}^{+} / \mathrm{Ca}^{++}$das raízes onde, em $100 \mathrm{~mol} \mathrm{~m}^{-3} \mathrm{de} \mathrm{NaCl}$, a cultivar BR-5011 apresentou valores $60 \%$ mais elevados que a P-3051. Analisando-se conjuntamente as diferentes partes das plantas, observa-se que, de modo geral, as maiores relações $\mathrm{Na}^{+} / \mathrm{K}^{+}, \mathrm{Na}^{+} / \mathrm{Ca}^{++} \mathrm{e}$ $\mathrm{Na}^{+} / \mathrm{Mg}^{++}$foram encontradas na raiz, no colmo e na bainha e, as menores, no limbo. A literatura evidencia, de forma inequívoca, que incrementos nas concentrações de sódio no ambiente radicular das plantas promovem a elevação da relação $\mathrm{Na}^{+} / \mathrm{K}^{+}$(Hajibagheri et al., 1987; Erdei \& Taleisnik, 1993; Cramer et al., 1994) e, também, da relação $\mathrm{Na}^{+} / \mathrm{Ca}^{++}$(Izzo et al., 1991) e $\mathrm{Na}^{+} / \mathrm{Mg}^{++}$(Araújo, 1994).

A relação $\mathrm{Na}^{+} / \mathrm{K}^{+}$é um dos fatores intimamente relacionados ao grau de tolerância à salinidade. Desta forma, ela pode ser utilizada como índice para toxicidade de sódio, devido ao fato deste íon inibir a atividade das enzimas que requerem potássio (Greenway \& Munns, 1980). Os autores reportaram, ainda, que relações $\mathrm{Na}^{+} / \mathrm{K}^{+}$iguais ou menores que 0,6 são necessárias para uma ótima eficiência metabólica em não-halófitas.
Hajibagheri et al. (1987) trabalhando com uma variedade de milho tolerante e outra sensível ao estresse salino, verificaram que a relação $\mathrm{Na}^{+} / \mathrm{K}^{+}$citoplasmática da sensível foi duas vezes superior à da tolerante, indicando maior eficiência desta última em seqüestrar o sódio citoplasmático para os vacúolos. A despeito da relação $\mathrm{Na}^{+} / \mathrm{K}^{+}$no limbo não ter sido significativamente diferente entre ambas as cultivares, é possível que a P-3051 tenha sido mais hábil em isolar sódio nos vacúolos, mantendo uma relação $\mathrm{Na}^{+} / \mathrm{K}^{+}$citoplasmática mais baixa, conduzindo a uma maior eficiência metabólica das folhas (Greenway \& Munns, 1980).

$\mathrm{O}$ aumento das relações $\mathrm{Na}^{+} / \mathrm{K}^{+}, \mathrm{Na}^{+} / \mathrm{Ca}^{++}$e $\mathrm{Na}^{+} / \mathrm{Mg}^{++}$nas partes das plantas com o incremento da salinidade, indica acréscimo na absorção de sódio em detrimento da absorção do nutriente em questão, conduzindo a um desequilíbrio iônico nas plantas (Cusido et al., 1987). Este desequilíbrio na absorção iônica resulta, provavelmente, da redução nas seletividades $\mathrm{K}^{+}-\mathrm{Na}^{+}, \mathrm{Ca}^{++}-\mathrm{Na}^{+}$e $\mathrm{Mg}^{++}-\mathrm{Na}^{+}$nas raízes (Porcelli et al., 1995) decorrente da perda da integridade das membranas (Cramer et al., 1985).

Analisando-se os teores de sódio, potássio, cálcio e magnésio e suas relações nas diferentes partes das plantas, observa-se que as relações entre os nutrientes revelaram-se indicadores mais realísticos do desequilíbrio entre esses íons, sugerindo que, para as cultivares em questão, o estudo das relações iônicas pode ser mais importante que a análise das concentrações absolutas isoladamente (Izzo et al., 1991). Por conseguinte, a manutenção de relações $\mathrm{Na}^{+} / \mathrm{Ca}^{++}$e Na$/ \mathrm{Mg}^{++}$ mais baixas nas partes da planta metabolicamente mais ativas (raiz, bainha e limbo) na P-3051 sugere um nível mais baixo de desequilíbrio iônico e, em conseqüência, maior atividade

Tabela 4. Relações ${ }^{1}$ sódio/potássio, sódio/cálcio e sódio/magnésio na matéria seca das diferentes partes das cultivares de milho P-3051 (tolerante) e BR-5011 (sensível) aos 21 dias após o transplantio, em função dos níveis de $\mathrm{NaCl}$ utilizados na solução nutritiva

\begin{tabular}{|c|c|c|c|c|c|c|c|c|}
\hline \multirow{3}{*}{$\begin{array}{l}\text { Níveis de } \\
\left.\mathrm{NaCl}^{-3}\right) \\
\left(\mathrm{mol} \mathrm{m}^{-3}\right)\end{array}$} & \multicolumn{8}{|c|}{ Partes das Plantas } \\
\hline & \multicolumn{2}{|c|}{ Raiz } & \multicolumn{2}{|c|}{ Colmo } & \multicolumn{2}{|c|}{ Bainha } & \multicolumn{2}{|c|}{ Limbo } \\
\hline & $\mathrm{P}-3051$ & BR-5011 & P-3051 & BR-5011 & P-3051 & BR-5011 & P-3051 & BR-5011 \\
\hline & \multicolumn{8}{|c|}{$\mathrm{Na}^{+} / \mathrm{K}^{+}$} \\
\hline 0 & $0,04 \mathrm{Ad}$ & $0,05 \mathrm{Ab}$ & $0,02 \mathrm{Aa}$ & $0,02 \mathrm{Ab}$ & $0,01 \mathrm{Ac}$ & $0,01 \mathrm{Ad}$ & $0,03 \mathrm{Ac}$ & $0,03 \mathrm{Ad}$ \\
\hline 25 & $1,82 \mathrm{Ac}$ & $1,85 \mathrm{Aa}$ & $0,65 \mathrm{Aa}$ & $0,78 \mathrm{Ab}$ & $0,29 \mathrm{Abc}$ & $0,35 \mathrm{Acd}$ & $0,39 \mathrm{Abc}$ & 0,36 Acd \\
\hline 50 & $3,13 \mathrm{Ab}$ & $2,62 \mathrm{Aa}$ & $1,25 \mathrm{Aa}$ & $1,88 \mathrm{Ab}$ & $0,47 \mathrm{Ab}$ & $0,61 \mathrm{Ac}$ & $0,61 \mathrm{Ab}$ & $0,64 \mathrm{Abc}$ \\
\hline 75 & $4,15 \mathrm{Aa}$ & $2,48 \mathrm{Ba}$ & $1,97 \mathrm{Ba}$ & $8,66 \mathrm{Aa}$ & $1,26 \mathrm{Aa}$ & $1,27 \mathrm{Ab}$ & $1,10 \mathrm{Aa}$ & $0,88 \mathrm{Ab}$ \\
\hline 100 & $2,82 \mathrm{Ab}$ & 2,81Aa & $2,99 *$ & $14,09^{*}$ & $1,54 \mathrm{Ba}$ & 2,34Aa & $1,27 \mathrm{Aa}$ & $1,47 \mathrm{Aa}$ \\
\hline \multirow[t]{2}{*}{ C. V. } & $13,98 \%$ & $13,98 \%$ & $15,80 \%$ & $15,80 \%$ & $19,55 \%$ & $19,55 \%$ & $20,03 \%$ & $20,03 \%$ \\
\hline & \multicolumn{8}{|c|}{$\mathrm{Na}^{+} / \mathrm{Ca}^{++}$} \\
\hline 0 & $0,16 \mathrm{Ac}$ & $0,18 \mathrm{Ad}$ & $0,18 \mathrm{Ad}$ & $0,20 \mathrm{Ac}$ & $0,30 \mathrm{Ad}$ & $0,17 \mathrm{Ac}$ & $0,14 \mathrm{Ad}$ & $0,22 \mathrm{Ac}$ \\
\hline 25 & $6,56 \mathrm{Ab}$ & 7,90Ac & $6,54 \mathrm{Ac}$ & $5,88 \mathrm{Ab}$ & $4,48 \mathrm{Ac}$ & $3,65 \mathrm{Ab}$ & $2,71 \mathrm{Ac}$ & $2,59 \mathrm{Ab}$ \\
\hline 50 & $9,12 \mathrm{Ab}$ & $10,04 \mathrm{Ac}$ & $14,05 \mathrm{Ab}$ & $9,02 \mathrm{Bab}$ & $7,21 \mathrm{Abc}$ & $6,50 \mathrm{Ab}$ & $3,95 \mathrm{Abc}$ & $4,30 \mathrm{Ab}$ \\
\hline 75 & $13,00 \mathrm{Ba}$ & $19,03 \mathrm{Ab}$ & $18,85 \mathrm{Aa}$ & $13,13 \mathrm{Ba}$ & $8,61 \mathrm{Bb}$ & $12,87 \mathrm{Aa}$ & $5,82 \mathrm{Bb}$ & $8,28 \mathrm{Aa}$ \\
\hline 100 & $16,00 \mathrm{Ba}$ & $25,65 \mathrm{Aa}$ & $25,61^{*}$ & $20,25^{*}$ & $13,51 \mathrm{Ba}$ & $15,64 \mathrm{Aa}$ & $8,65 \mathrm{Aa}$ & $9,73 \mathrm{Aa}$ \\
\hline \multirow[t]{2}{*}{ C. V. } & $16,96 \%$ & $16,96 \%$ & $19,55 \%$ & $19,55 \%$ & $12,31 \%$ & $12,31 \%$ & $12,80 \%$ & $12,80 \%$ \\
\hline & \multicolumn{8}{|c|}{$\mathrm{Na}^{+} / \mathrm{Mg}^{++}$} \\
\hline 0 & $0,11 \mathrm{Ad}$ & $0,13 \mathrm{Ac}$ & $0,17 \mathrm{Ad}$ & $0,20 \mathrm{Ad}$ & $0,22 \mathrm{Ac}$ & $0,18 \mathrm{Ae}$ & $0,24 \mathrm{Ad}$ & $0,32 \mathrm{Ad}$ \\
\hline 25 & $4,69 \mathrm{Ac}$ & $4,92 \mathrm{Ab}$ & $5,43 \mathrm{Ac}$ & $6,59 \mathrm{Ac}$ & $3,92 \mathrm{Ab}$ & $4,69 \mathrm{Ad}$ & $3,35 \mathrm{Ac}$ & $4,16 \mathrm{Ac}$ \\
\hline 50 & $6,37 \mathrm{Abc}$ & $5,57 \mathrm{Ab}$ & $8,98 \mathrm{Bb}$ & $11,92 \mathrm{Ab}$ & $6,56 \mathrm{Ab}$ & 7,69Ac & $4,99 \mathrm{Bbc}$ & $7,06 \mathrm{Ab}$ \\
\hline 75 & $7,00 \mathrm{Ab}$ & $6,64 \mathrm{Ab}$ & $13,51 \mathrm{Ba}$ & $23,33 \mathrm{Aa}$ & $11,70 \mathrm{Aa}$ & $13,16 \mathrm{Ab}$ & $6,35 \mathrm{Bb}$ & $9,04 \mathrm{Aa}$ \\
\hline 100 & $9,87 \mathrm{Ba}$ & $11,91 \mathrm{Aa}$ & $15,34 *$ & $25,72 *$ & $13,77 \mathrm{Ba}$ & $15,53 \mathrm{Aa}$ & $8,72 \mathrm{Ba}$ & $10,10 \mathrm{Aa}$ \\
\hline C. V. & $19,77 \%$ & $19,77 \%$ & $11,91 \%$ & $11,91 \%$ & $19,76 \%$ & $19,76 \%$ & $11,69 \%$ & $11,69 \%$ \\
\hline
\end{tabular}

${ }^{1}$ Médias seguidas de mesmas letras, maiúsculas para cultivares e minúsculas para níveis, não diferem pelo teste de Tukey, a nível de $5 \%$ *Amostras analisadas conjuntamente 
metabólica por parte desta cultivar, o que pode ter sido um importante fator, conferindo seu caráter de tolerância à salinidade.

\section{CONCLUSÕES}

1. Nas cultivares avaliadas, a adição de cloreto de sódio na solução nutritiva eleva os teores de sódio na raiz (48 vezes), colmo (58 vezes), bainha (74 vezes) e limbo (20 vezes).

2. A salinidade também reduz os teores de potássio na raiz (31\%), colmo (82\%), bainha (45\%) e limbo (34\%) das cultivares analisadas.

3. A acumulação preferencial de sódio nos tecidos do colmo e da bainha, em detrimento do limbo, é um dos mecanismos de tolerância à salinidade utilizados pelas plantas estudadas.

4. Os tratamentos salinos reduziram os teores de cálcio na raiz (60\%), no colmo (49\%) e limbo (39\%) das plantas, ao passo que os de magnésio só são diminuídos na raiz (48\%) e no colmo (47\%).

5. Sob condições de elevada salinidade, o teor de cálcio mais elevado nas raízes da cultivar P-3051 é o parâmetro nutricional, que melhor se correlaciona com seu caráter de tolerância ao estresse salino, quando comparado com a BR5011.

6. Os incrementos nos tratamentos salinos elevam as relações $\mathrm{Na}^{+} / \mathrm{K}^{+}, \mathrm{Na}^{+} / \mathrm{Ca}^{++}$e $\mathrm{Na}^{+} / \mathrm{Mg}^{++}$em todas as partes das plantas, sendo este efeito mais evidente na cultivar BR-5011 que na P-3051. Estas relações revelam-se, portanto, variáveis importantes no estudo nutricional das plantas sob condições de estresse salino.

\section{REFERÊNCIAS BIBLIOGRÁFICAS}

ALBERICO, G.J.; CRAMER, G.R. Is the salt tolerance of maize related to sodium exclusion? I. Preliminary screening of seven cultivars. Journal of Plant Nutrition, New York, v.16, p.2289-2303, 1993.

ARAÚJO, C.A.S. Avaliação de feijoeiros quanto a tolerância à salinidade em solução nutritiva. Viçosa: UFV, 1994. 87p. Dissertação Mestrado

AZEVEDO NETO, A.D. Estudo do crescimento e distribuição de nutrientes em plântulas de milho submetidas ao estresse salino. Recife: UFRPE, 1997. 134p. Dissertação Mestrado

AZEVEDO NETO, A.D.; BARRETO, L.P.; BEZERRA NETO, E. Efeito da salinidade sobre os teores de macronutrientes em duas cultivares de sorgo cultivadas em solução nutritiva. In: CONGRESSOBRASILEIRODA CIÊNCIA DOSOLO, 25, 1995, Viçosa. Resumos expandidos... Viçosa: SBCS, 1995. v. 3, p.1345-1347.

BOURSIER, P.; LÄUCHLI, A. Growth responses and mineral nutrient relations of salt-stressed sorghum. Crop Science, Madison, v.30, p.1226-1233, 1990.

BOURSIER, P.; LYNCH, J.; LÄUCHLI, A.; EPSTEIN, E. Chloride partioning in leaves of salt-stressed sorghum, maize, wheat and barley. Australian Journal of Plant Physiology, Melbourne, v.14, p.463-473, 1987.

CHEESEMAN, J.M. Mechanisms of salinity tolerance in plants. Plant Physiology, Rockville, v.87, p.547-550, 1988.
CLARKSON, D.T.; HANSON, J.B. The mineral nutrition of higher plants. Annual Review of Plant Physiology, Palto Alto, v.3, p.239-298, 1980.

COLMER, T.D.; FAN, T.W.M.; HIGASHI, R.M.; LÄUCHLI, A. Interactions of $\mathrm{Ca}^{2+}$ and $\mathrm{NaCl}$ stress on the relations and intracellular $\mathrm{pH}$ of Sorghum bicolor root tips: An in vivo ${ }^{31} \mathrm{P}-\mathrm{NMR}$ study. Journal of Experimental Botany, Oxford, v.45, p.1037-1044, 1994.

CRAMER, G.R.; ALBERICO, G.J.; SCHMIDT, C. Salt tolerance is not associated with the sodium accumulation of two maize hybrids. Australian Journal of Plant Physiology, Melbourne, v.21, p.675-692, 1994.

CRAMER, G.R.; LÄUCHLI, A.; POLITO, V.S. Displacement of $\mathrm{Ca}^{2+}$ by $\mathrm{Na}^{+}$from the plasmalemma of root cells. A primary response to salt stress? Plant Physiology, Rockville, v.79, p.207-211, 1985.

CUSIDO, R.M.; PALAZON, J.; ALTABELLA, T.; MORALES, C. Effect of salinity on soluble protein, free amino acids and nicotine contents in Nicotiana rustica L. Plant and Soil, Dordrecht, v.102, p.55-60, 1987.

ERDEI, L.; TALEISNIK, E. Changes in water relation parameters under osmotic and salt stresses in maize and sorghum. Physiologia Plantarum, Copenhagen, v.89, p.381-387, 1993.

FOUGÈRE, F.; LE RUDULIER, D.; STREETER, J.G. Effects of salt stress on amino acid, organic acid, and carbohydrate composition of roots, bacteroids, and cytosol of alfafa (Medicago sativa L.). Plant Physiology, Rockville, v.96, p.1228-1236, 1991.

GOMES, F.P. Curso de estatística experimental. 12.ed. Piracicaba: Nobel, 1987, 430p.

GREENWAY, H.; MUNNS, R. Mechanisms of salt tolerance in nonhalophytes. Annual Review of Plant Physiology, Palto Alto, v.31, p.149-190, 1980.

HAJIBAGHERI, M.A.; HARVEY, D.M.R.; FLOWERS, T.J. Quantitative ion distribution within root cells of salt-sensitive and salt-tolerant maize varieties. New Phytologist, Cambridge, v.105, p.367-379, 1987.

HOAGLAND, D.R.; ARNON, D.I. The water-cultured method for growing plants without soil. California: California Agricultural Experiment Station, 1950. 32p. Circular no 347

IZZO, R. NAVARI-IZZO, F.; QUARTACCI, F. Growth and mineral absorption in maize seedlings as affected by increasing $\mathrm{NaCl}$ concentrations. Journal of Plant Nutrition, New York, v.14, p.687-699, 1991.

JARREL, W.M.; BEVERLY, R.B. The dilution effect in plant nutrition studies. Advances in Agronomy, New York, v.34, p.197-224, 1981.

KAWASAKI, T.; AKIBA, T.; MORITSUGU, M. Effects of high concentrations of sodium chloride and polyethylene glycol on the growth and ion absorption in plants: I. Water culture experiments in a greenhouse. Plant and Soil, Dordrecht, v.75, p.75-85, 1983.

MARCUM, K.B.; MURDOCH, C.L. Salinity tolerance mechanisms of six $\mathrm{C}_{4}$ turfgrasses. Jounal of American Society of Horticultural Science, v.119, p.779-784, 1994.

MUNNS, R.; TERMAAT, A. Whole plant responses to salinity. Australian Journal of Plant Physiology, Melbourne, v.13, p.143-160, 1986. 
PORCELLI, C.A.; BOEM, F.H.G.; LAVADO, R.S. The K/Na and $\mathrm{Ca} / \mathrm{Na}$ ratios and rapeseed yield, under soil salinity or sodicity. Plant and Soil, Dordrecht, v.175, p.251-255, 1995.

RAHMAN, S.; VANCE, G.F.; MUNN, L.C. Salinity induced effects on the nutrient status of soil, corn leaves and kernels. Communication of Soil Science and Plant Analysis, New York, v.24, p.2251-2269, 1993.

RICHARDS, L.A. Suelos salinos y sodicos: diagnostico y rehabilitacion. 6.ed. México: Editorial Limusa, 1974. 172p.

SARRUGE, J.R.S.; HAAG, H.P. Análises químicas em plantas. Piracicaba: USP-ESALQ, 1974. 56p.

SCHUBERT, S.; LÄUCHLI, A. Sodium exclusion mechanisms at the root surface of two maize cultivars. Plant and Soil, Dordrecht, v.123, p.205-209, 1990.
SPICKETT, C.M.; SMIRNOFF, N.; RATCLIFFE, R.G. An in vivo nuclear magnetic resonance investigation of ion transport in maize (Zea mays) and Spartina anglica roots during exposure to high salt concentrations. Plant Physiology, Rockville, v.102, p.629-638, 1993.

TAIZ, L.; ZEIGER, E. Plant Physiology. Redwood City: The Benjamin/Cummings publishing Co., 1991.565p.

ULLAH, S.M.; SOJA, G.; GERZABEK, M.H. Ion uptake, osmoregulation and plant-water relations in faba beans (Vicia faba L.) under salt stress. Die Bodenkultur, Viena, v.44, p.291-301, 1993.

WYN JONES, R.G.; GORHAM, J. Osmoregulation. In: LANGE, D.L.; NOBEL, P.S.; OSMOND, C.B.; ZIEGLER, H. Encyclopedia of plant physiology: physiological plant ecology III - Response to chemical and biological environment. Berlin: Springer-Verlag, 1983. p.35-58. 